\title{
THE ROLE OF THE VISITING NURSE IN THE CAMPAIGN FOR PUBLIC HEALTH
}

\author{
By C. E. A. WINSLOW \\ Associate Professor of Biology, College of the City of New York, and Curator of Public Health, \\ American Museum of Natural History, New York.
}

IT would be somewhat more than a play upon words to say that the campaign for public health is passing at present through a humanistic stage. In other words attention is directed to the human body as the source and centre of disease rather than to the more remote environment which filled so large a place in the thoughts of an earlier generation. Sanitarians of thirty years ago were mainly concerned with the dangers from swamps and refuse heaps and plumbing pipes and fomites. We are not greatly exercised about these things but focus our attention chiefly upon the original source of the disease germ, the infected human body, whether of the frankly sick or of the carrier class. The emphasis is upon persons where it was once chiefly upon things.

It is of course true that pathogenic germs are spread from person to person by various inanimate vehicles of disease. Polluted water, polluted or decayed milk, and insects may all carry infection. Filthy conditions of living act as the nurse if not the mother of disease. Yet in all these cases the human body is the original source of infection. The extent of the danger bears an inverse relation to the length of time which elapses in transit. In all the diseases, except those carried by certain insect hosts, direct contagion plays a more or less important part.

Public sanitation, including the care of the environmental factors, the protection of water and foods, the disposal of wastes, the conditioning of the atmosphere and the like, has its own field. Yet it is, I think, more and more clear that the real strategic point is by the bedside of the patient and at the elbow of the convalescent or the carrier. Here the chain of infection can be broken far more surely and more economically than at any other point. The prompt detection of infected persons and their isolation are the most effective of all methods of stopping the spread of communicable disease and the most universal, if one interprets isolation broadly. Effective isolation may mean complete separation of the infected individual from all personal contact, as in smallpox, or it may be attained merely by the systematic disinfection of excreta, as in tuberculosis and in typhoid fever. In any case the control of these diseases requires intimate supervision and detailed regulation of 
personal conduct which depends in practice upon the individual instruction of a trained expert. Such a trained expert will usually be a nurse; and this is the first important role of the visiting nurse in the campaign for public health.

Beyond all the agencies which deal chiefly with the checking of specific maladies, there is to-day opening up a new field of public-health activity in which the preservation of health, rather than the prevention of disease, holds a pre-eminent place. Public sanitation deals with the larger problems of our common municipal life, with the purification of water supplies, the supervision of milk supplies, the disposal of municipal wastes, the sanitation of living and work places. Private sanitation reaches out into the conduct of the individual life, preventing the discharge of infected excreta into the general environment and protecting the individual, as far as possible, against the subtler methods of transmission of prosodemic disease. Of equal importance, and in many instances of even more importance, is the problem of personal hygiene which deals not with specific diseases but with the maintenance by proper food and exercise and rest and atmospheric conditions of a sound physical tone which will enable the body to meet and repel an occasional invading microbe.

We owe our real recognition of the importance of personal hygiene and our practical methods of disseminating this knowledge chiefly to the campaign against tuberculosis. In the case of this disease it was quite clear that the most important of all measures were those which built up the vital resistance of the body and maintained the fighting edge which is so effective against this particular microbic enemy. Sanitary shops and tenements were needed, the sanitary care of sputum was needed; but above all healthy halsits of individual living were essential. Hence the anti-tuberculosis movement became a great campaign of popular education. It was animated by a new idea, the idea of bringing hygienic knowledge right to the individual in his home or in his shop; and it developed a new machinery, a new system of organization for bringing about this end. In doing this work, the medical and sanitary experts and particularly the social workers not only pointed the way to a conquest of the great white plague but set in motion forces which are revolutionizing the campaign for public health in every field.

The same thing has happened more recently in the movement for the reduction of infant mortality. Budin began his conferences with nursing mothers in 1894, but for ten years more public health officials were chiefly concerned with ineffectual attempts to improve an artificial milk supply while the central features of the problem, the child and the mother, 
were ignored. When the first American Conference for the Prevention of Infant Mortality was held at New Haven in 1909 it was surprising to see how experience from every organization dealing with the problem had focused on a single point. Man after man said in effect that he had come to feel that the success of a station could be gauged not by the quarts of milk distributed but by the nursing mothers under instruction. The movement for the reduction of infant mortality became at that meeting, consciously and definitely, an educational one; and its prime task is to-day recognized, as clearly as in the case of tuberculosis, to be the task of carrying sanitary and hygienic knowledge into the individual home.

Education then is the keynote of the modern campaign for public health. Tuberculosis and infant mortality are pre-eminent among all the causes of preventable disease and death as the two greatest scourges, in the abatement of which the largest results for humanity are to be attained. In each case the fight must be won not by the construction of public works but by the conduct of the individual life. The same thing is true with regard to the spread of the acute contagia, the burden of venereal disease, the obscure ill effects of defective eyes and ears and teeth and a dozen other problems which in greater or less degree concern the public health. In every one of these cases the results we are striving for can only be reached by spreading a clear knowledge of the ways in which disease spreads, and the ways in which it is prevented, among the mothers who bring up the babies and the men who pay rent in the tenements and work in the stores and factories.

We need expert sanitary engineers to build and operate our public works; we need sanitary physicians to deal with the broader communal aspects of the spread of communicable disease; we need sanitary bacteriologists and chemists and statisticians to furnish the special expert knowledge by which all these activities must be guided. More than all, however, we need large bodies of sanitary educators who can bring our knowledge to bear on the individual citizen who alone can make so much of it effective. Some of these missionaries of sanitation will be physicians, but most of them will be of your profession. And that is why in my judgment the visiting nurse is the most important figure in the modern movement for the protection of the public health,---even if I state the case more moderately than did a student of mine in a recent examination paper. As he put it, "The nurse is the Grant, the Blucher of the campaign. She has come up with her splendid training, her many talents, her ready sympathy and mother heart at the crisis in the battle. Those who have fought long and hard may take courage. The victory will be won. Waterloo is in sight." 
Three fields for the activity of the visiting nurse have already been fairly well mapped out, those which are concerned with school inspection, with tuberculosis, and with the reduction of infant mortality. The history of the movement for school nursing is a brief but an instructive one. The visits of a district nurse to a single school in a poor district of London, in 1894, were so fruitful as to arouse the interest of Miss Honnor Morten, herself a nurse and a social worker and a member of the London School Board. A voluntary “School Nurses' Society" was founded in 1898 and three nurses were appointed, each with four schools under her care. The School Board later provided a basin and kettle for the use of the nurse in each school with the proviso that the expense of the two articles should not exceed three shillings, and still later provided a single nurse for the three and a half million children in the schools. In 1904 the whole work was seriously taken up by the School Board and a staff of official nurses appointed, but their work was limited to reporting, excluding from school, and distributing printed circulars, eliminating the most important part of the whole, the instructional visiting in the home.

School nursing in the United States was begun in a similar way by private enterprise, and is one of the many fine things we owe to Miss Lillian Wald of the Henry Street Settlement in New York. Following Miss Morten's work in London, Miss Wald in 1902 offered to place one of her staff in the schools for an experiment. The demonstration was so conclusive that in the next year at the request of Dr. Lederle, Commissioner of Health, $\$ 30,000$ was appropriated for an official beginning of the work. To-day 157 nurses are employed in school inspection and in the instruction of mothers in the care of children. Dr. S. Josephine Baker, Director of Child Hygiene to the New York Department, writes of the present organization as follows:

"In public health work, particularly among children, the trained nurse is the link between mere compiling of statistics and applied results. Believing that it is the true function of health authorities to make their efforts preventive rather than corrective, the methods employed must be almost wholly educational in order to be effective. Experience has shown us that educational health work can be carried on with a certain degree of success by the use of popular bulletins, pamphlets, lectures and other forms of general instruction, but when dealing with specific instances of health in the family the most direct and surest way is to make an individual personal appeal to the family itself. In this work the trained nurse has found a new field of work and her employment by municipal boards of health has been of inestimable value. 
"In the school the nurse's main duty is to detect cases of contagious eye and skin diseases and to see that they obtain treatment, either by private physicians or dispensaries or by treating them herself in the school. The former method, before the employment of the school nurse, consisted in excluding all children so affected until treatment was obtained. These children rarely obtained treatment, owing to poverty or neglect, and the fact that the ailment was in many instances so slight that any expenditure for medical care was considered unwarranted. The consequent truancy and loss of school time was enormous. An interesting and conclusive comparison is that of the years 1902 and 1910 or 'before and after' the use of the nurse. In 1902, 53,903 children were excluded from school attendance for these minor contagious diseases. In 1910 it was necessary to exclude only 4131 children, in instances where the disease was in such an acute stage that even with continued treatment school attendance was not considered safe. The gain in school time alone has more than offeet any expenditure in salaries. To accomplish this result the nurses gave 89,116 treatments in school in 1910, exclusive of the cases of pediculosis and trachoma, where instructions and supervision of outside treatment are required.

"In 1905 the department instituted the practice of physical examination of each school child to determine the existence of any noncontagious physical defect interfering with the general health of the child or its school progress. Whenever defects were found notice was sent to the parents, advising them to take the child to a physician or dispensary for treatment; return postals were furnished to report to the department the action taken. About 6 per cent. of the children were placed under medical care. With the establishment of the Division of Child Hygiene in 1908 this method was discontinued and all cases are now referred to the nurse who visits the home, explains the necessity of treatment, follows up the case by repeated visits until treatment is obtained or absolute refusal is met. During 1910, 74 per cent. of all children followed up received medical attention. Mere figures can give no idea of the educational and social value of this work. It has meant remedying home conditions, correcting unsanitary and unhygienic living surroundings, adjusting dietaries, and rendering the whole home life of the child safer, more wholesome and more healthful. The educational value has been profound. When defects already existed correction is essential, but the awakening of parents to a sense of responsibility in this direction has resulted in an entirely different mental attitude towards all of the children in the family and a desire to learn the ways and methods for the prevention of such conditions in the future. The 
effect on the children themselves is even more marked. The influence of the nurse is shown in greater attention to cleanliness, hygiene and health. So long as there is no scientific standard of school advancement or promotion no definite study of the relation of school progress to physical defects can be made, but from the point of view of the child as a child the results have clearly shown that the health standard is definitely higher even in the short time under consideration. Its value to the next generation cannot be doubted."

The example of New York was quickly followed. Miss Yssabella Waters in her book on "Visiting Nursing in the United States" (1909) lists 24 cities which at that time employed school nurses, including Berkeley, Los Angeles and San Francisco in California; Pueblo, Colorado; Atlanta, Ga.; Seattle and Tacoma, Wash., and most of the large eastern and middle-western cities. The whole subject of the school nurse has been admirably treated in a recent monograph by Miss Isabel M. Stewart and Miss M. Adelaide Nutting in the Ninth Yearbook of the National Society for the Study of Education. Its present status is well summed up in the paragraph which they quote from Gulick and Ayres' "Medical Inspection of Schools":

"To sum up the case for the school nurse, she is the teacher of the parents, the pupils, the teachers, and the family in applied practical hygiene. Her work prevents loss of time on the part of the pupils and vastly reduces the number of exclusions for contagious diseases. She cures minor ailments in the school and furnishes efficient aid in emergencies. She gives practical demonstrations in the home, of required treatments, often discovering there the source of the trouble, which, if undiscovered, would render useless the work of the medical inspector in the school. The school nurse is the most efficient possible link between the school and the home. Her work is immensely important in its direct results and very far-reaching in its indirect influences. Among foreign populations she is a very potent force for Americanization."

The application of the educational force of visiting nursing to the problem of tuberculosis was again due to the far-sightedness and organizing ability of Miss Wald; and she presented an excellent summary of the history and significance of the movement before Section $\nabla$ of the Sixth International Congress on Tuberculosis. As early as 1893, when the Henry Street Settlement was organized, definite plans were made for the instruction of tuberculosis patients. The New York City Department of Health began its splendid campaign against tuberculosis in the next year, 1894, but its official staff of nurses was not organized until nine years later. Dr. Osler inaugurated a system of home instruc- 
tion for the tuberculous in Baltimore in 1899. It was only after 1904 that these pioneer efforts were merged in the greater popular antituberculosis movement which has done so much not only for the restriction of the particular disease with which it is concerned, but for the regeneration of the whole campaign for public health along new and effective lines. Since January, 1905, anti-tuberculosis organizations have increased from 24 to 511, sanitoria, hospitals and day camps from 115 to 421 , dispensaries from 19 to 342 . In this new field of social hygiene the nurse has come to play a more and more important part; for the campaign against tuberculosis is primarily a matter of individual conduct, care of the excreta on the sanitary side and rational treatment of the living machine on the hygienic side. There are other aspects of the question, where it touches municipal sanitation in respect to the construction of living and work places and where it deals with the economic conditions which are so intimately interwoven with preventable disease. Yet the most direct and immediate method of attacking this complex problem lies along the line of personal instruction and the function of the visiting nurse becomes of supreme importance. Miss Wald, in the paper to which reference has been made, lists 33 states and 59 cities as having placed tuberculosis nurses at work, while $\% 0$ associations of nurses were then working solely in the tuberculosis campaign.

The third important field for the visiting nurse is in the reduction of infant mortality, the newest and one of the most hopeful of all forms of public health activity. The systematic organization of this movement on a large scale dates only from the formation of the American Association for the Study and Prevention of Infant Mortality at New Haven in 1909. At that meeting, however, New York, Chicago, and Philadelphia could already report good beginnings and in other cities, as in Boston, philanthropic agencies were carrying forward the same work under private auspices. It is clearly recognized to-day that there is just one effective way to cope with the great evil of infant mortality, the instruction of the individual mother, so that she may give her bahy its normal food and may intelligently care for it in other ways. Here as in the case of tuberculosis there are sociological factors which must some day be dealt with. Poverty and ignorance, as Dr. Holt has said, are the twin roots from which the evil springs. Yet just because the problem of poverty is beyond our reach as yet, we should strive the more earnestly to cope with the ignorance which lies within our grasp. Again, therefore, the visiting nurse holds the key to the situation. Dr. J. H. Mason Knox, late president of the American Association for Study and Prevention of Infant Mortality, writes as follows in the Visiting Nurse 
Quarterly for July, 1910: "In the last analysis, however, all our work hinges upon the better care of individual babies coming under our influence, and it is here that the trained nurse should be given the first place, both because of her unique opportunity and because of the good results which she has and does accomplish. It is she who enters the home, a welcome visitor, but one armed with expert knowledge and kindly act. It is she who can open the closed windows, remove superfluous clothes, prepare the baby's feedings, give it a bath as an object lesson to the mother, and perform a hundred other services which together mean the difference between life and death."

Miss Nutting has pointed out that Florence Nightingale had a clear vision of these new developments in their main outlines many years ago. She spoke of "Health Nursing" as distinguished from " Sick Nursing," and pointed out that "The same laws of health or of nursing, for they are in reality the same, obtain among the well as among the sick. The breaking of them produces only less violent consequences among the former than among the latter, and this sometimes, not always." "We have medical officers, immense sanitary works; we have not nursesmissioners of health-at-home."

(This is the crux of the whole movement for the public health to-day. The maintenance of health by education is more and more the aim of the social worker and the public health official; and the establishment of a corps of nurses by the Metropolitan Life Insurance Company is a striking indication of the practical financial value of such efforts. I look to see an unprecedented development of preventive measures along lines of which we scarcely dream to-day. The medical inspection of schools began with the idea of preventing the spread of acute contagious disease from one pupil to another, an orthodox sanitary function. It soon included less acute communicable diseases and finally purely individual physical defects, and these latter to-day occupy an overwhelming proportion of the energies of the school doctor and the school nurses. In New York City in the last half of 1908 the school nurses dealt only with 1868 cases of acute contagion against 121,738 cases of communicable diseases of the skin and eye and 247,211 cases of non-contagious physical defects. There is no sound logical reason why the community should take an active part in dispelling the ignorance that leads to tuberculosis and infant mortality while leaving its citizens unaided in coping with diseases of the arteries, the kidneys and the nervous system.

We have been considering so far only the more direct and obvious functions of the visiting nurse in relation to the sanitary and hygienic 
education of the individuals who come under her charge. She has also many opportunities, if she is qualified to avail herself of them, to play an important part in the general movement for better municipal sanitation and in the broad scientific and sociological investigations which underlie the public health campaign. The inspection of factories and schools and tenements with respect to the physical environment, to atmospheric conditions and lighting, sanitary conveniences, and general cleanliness and the protection of the worker from industrial accidents and industrial poisoning-all these functions can well be performed by a trained nurse who can deal at the same time with the physiological condition of the occupants-provided, of course, that she has acquired the requisite sanitary training. Finally, the visiting nurse must be in her field a research worker, a "social reporter" as Miss Wald has called her. She is in touch with all the practical phases of the problem as no one else can be. She can render a great service in the accumulation of information as to the importance of various factors in disease which we so much need to build up the quantitative sanitary science of the future. As Miss Mary E. Lent has said of the tuberculosis nurse, "She can put the facts so strongly before the public that the state will finally be obliged to take measures to accomplish what she herself has been unable to do. She is able to unearth, and expose to the public, conditions whose existence no one else could suspect. Her opportunities in this line are unlimited. She cannot stamp out tuberculosis by teaching her patients, but she can do an enormously important work toward the same end by enlightening the general public in regard to the facts of the case, and interpreting for them the conditions that render futile the present efforts to eliminate the disease."

All this requires obviously enough a highly trained and specialized expert. I have no knowledge of the requisites for "Sick Nursing"; but it is quite clear that in public health work the visiting nurse must be no empirically trained upper bedside servant. She must understand thoroughly the general fundamental laws of hygiene and sanitation, which means a mastery of the principles of physiology and bacteriology, and she must have a minute grasp of their special applications in the field of her own work, whether it be school nursing, tuberculosis nursing or infant hygiene. She must know these things not merely as a practitioner but as a teacher, which means not only a knowledge of details but a vision of their right relationship and a talent for effective presentation.

She must in addition to all this be equipped with a knowledge of the economic conditions and the sociological principles which intimately touch her work at a hundred different points. A speaker at the Tuber- 
culosis Congress quoted "a Boston physician, well to the fore in the antituberculosis movement, who said that he would rather have the trained social worker for tuberculosis work than the graduate nurse who had no knowledge of social and economic questions;" and there are many who would agree with this opinion.

'The mere rehearsal of such qualifications is almost an arraignment of the present system of nursing education, in despite of which so many nurses have achieved notable things for themselves and for the community. As Miss Stewart and Miss Nutting have said, this vocation " demands educated women, women who not only know how to do things but why they do them; women of broad sympathies and social understanding as well as practical skill. This enlarging field of nursing activities makes a new and direct call on the hospital training schools to uphold high standards of entrance requirements and to furnish a type of professional training which will fit the student not only for private and hospital service, but for the social and educational field as well."

(It is a matter of common knowledge that most hospital training schools are not prepared to meet these new needs and cannot meet them without external aid. Over a thousand such schools have come into existence since 1890 , but their establishment has been inspired less by educational ideals than by the desire to obtain unpaid assistance in the routine work of the hospital itself. Too often standards of admission, which are of such importance in a profession demanding unusual physical and mental and personal qualifications, are sacrificed to the need for student nurses to do the work. Too often the applicant, once admitted, is subjected to severe conditions of overwork and underfeeding and poor living accommodations. Always there are the educational weaknesses inherent in an undertaking which is not primarily educational in aim. The course is apt to be carelessly planned, the teachers those who chance to be available, the teaching what they happen to find it easiest to give and the laboratory equipment hopelessly inadequate. Most fundamental of all is the problem of time. It is absurd to attempt to train the nurses we need for the public health campaign by a course which involves two or three hours a week of theory and fifty to sixty hours in the wards, not hours of clinical instruction, but for the most part a routine of unenlightening and exhausting manual work. The relation between the hospital and the training school should be a symbiotic one; it more nearly resembles a case of simple parasitism. D

The solution of this whole problem may perhaps lie as in other cases in the recognition that the genus, Trained Nurse, must be special- 
ized to deal with the diverse duties which may be demanded of her. For some purposes complex instruments are needed while for others simpler ones will serve. Miss C. A. Aikens, in the 'Transactions of the 'Tenth Annual Conference of the American Hospital Association, makes a strong plea for a simpler and more practical training even than the present one. "Suppose we skipped the lessons on embryology and started with the sick man as he is when he comes into the hospital. Suppose we just put him to bed, clean him up, study his symptoms, and take the best care of him that we can." I suppose there is need for nurses of that kind and I can quite conceive that a smattering of halfdigested lectures may spoil a good bedside assistant without producing anything else. It is well perhaps that the training of such nurses for their high calling of faithful undistinguished service should be organized on the simplest and most practical lines. But this sort of education will not serve for the instructive visiting nurse in the public health campaign. She must have a sound grasp of the biological principles which underlie her work so that she ought to have as good a grounding as the medical man in the fundamentals of physiology and bacteriology and hygiene; and she must in certain directions go beyond what the physician, as a physician, can teach her, for she must be acquainted with the broad outlines of sanitation and sociology which lie outside his field.

It is obvious that this need can only be met by special institutions devoted to the training of nurses for the higher branches of their profession, institutions which while they are affiliated with hospitals are independent of them and exist primarily for purposes of education. Dr. F. P. Denny long ago presented the need for such an institution in an able paper in the Boston Medical and Surgical Journal for June 18, 1903. He points out that the nurse's education can only fit her for a profession rather than a manual trade if it includes sound theoretical instruction given under such conditions that she is not too exhausted by a day's labor to profit by it. For this purpose he suggests a course of study of at least one year dealing with fundamental principles before the beginning of hospital work. In view of the recent developments of social service and public health we may to-day emphasize as equally necessary the provision of special graduate instruction for nurses specializing in these various lines. For nurses of all classes, however, a sounder elementary training is essential, as urged not only by Dr. Denny but by Dr. Richard C. Cabot and Mrs. Hunter Robb in this country, and by Dr. Oldfield in England. The case has been most forcibly presented by Professor Nutting of Teachers' College in a paper read before the Tenth Annual Conference of the American Hospital Association and 
in the joint paper with Miss Stewart to which reference has been made. 'There are indeed as she says those "who feel that in the best interests of both hospital and training school some reconstruction of (the present) system is necessary; that much of the teaching, especially all of that fundamental work included in the preparatory course now given in the hospital, should be given outside of it in a central school which could do for a number of hospitals what each one is now trying to do for itself; and that this central school should take upon itself the direction of the education and responsibility of arranging with different hospitals for the practical training of the pupil in all the various services. In other words, that the training school should rest upon a foundation not unlike the medical school."

(Miss Nutting has done more than criticise present conditions. She has made the first constructive effort to provide a remedy. She has organized at Teachers' College a Department of Nursing and Health which meets the graduate side of the problem by giving to holders of a high school certificate, or its equivalent, and a training school diploma, a course of one year designed specifically to prepare "teacher nurses" for district nursing, school nursing, tuberculosis and infant mortality nursing and other fields of municipal and social service. This points the way to a splendid opportunity for educational and philanthropic endeavor. It should be an affiliated part of a college of nursing and there should be such colleges wherever the financial and hospital facilities of a city make it possible.) Your profession and mine should unite in urging the need for such an institution until we can effectively arouse the interest of the friends of education and of human welfare. The problem is solely a financial one. Given the funds, a single college of this kind would in ten years so demonstrate its usefulness that more would easily follow. You nurses need it in order that your profession may attain its proper dignity and usefulness. We sanitarians need it in order that the campaign for the public health may be carried forward at its most critical and hopeful point.

The President: I am sure it is impossible for us to express our appreciation of this perfectly splendid address. As I sat here listening to it, it seemed to me like the crystallization of all that we had talked and hoped and dreamed of these years, given to us in a perfectly clear and concise way; I am sure that we shall go away with a great deal more courage to do the work that has been outlined.

Miss Nevins: I move that a very hearty vote of thanks be tendered Dr. Winslow for his wonderfully comprehensive exposition of our work, and furthermore that the Associated Alumns order a large number of reprints of his paper for distribution. (Carried.) 
Miss McIsanc: May I add something to what Miss Nevins has said? May 1 beg that every delegate here shall request every society to which she belongs to take up this paper of Professor Winslow's as part of its work for next year?

Miss Erdsedge: May I suggest in addition that a copy of this paper be sent to the superintendents of hospitals and training schools ?

Mrss Maxwanl: May I suggest that it also be sent to the trustees of hospitals?

The President : I think we will give the Committee on Publication directions to distribute this pretty generally, to the members of the association, superintendents of training schools and boards of managers of training schools.

The Report of the Public Health Committee should be presented by Mrs. A. R. Colvin, of St. Paul, Minnesota. Unfortunately Mrs. Colvin is not here, but I will call on Miss Anna Kerr, a member of the committee, and superintendent of the school nurses of New York City, to present this report.

Mrss Ansa Kerr.-Madam President, Ladies of the Alumnæ: This is not in any sense a report of the Public Health Committee, of which I am simply a member and a young member. After Professor Winslow's paper, which has covered almost everything that we hoped to do, I think perhaps you would be interested in what I can tell you of the practical work that we have done along the line that was taken up last year, that of teaching sex hygiene. The teaching of hygiene on that subject has not been taken up by the public health nurses, but it has been taken up by other bodies working along the same line, and we are in a position to know the results of that. I think pamphlets have been distributed on these subjects and given out to groups of children, not only in Manhattan, where I am working, but here in Boston, and I do not think the results have been altogether satisfactory to the educators who advocated them. In most cases those pamphlets were abandoned. We feel that they do not fill exactly the want that we have. The teaching which we hope to institute in the future will be along biological lines; and I think I can quote Dr. Cabot as saying that we should not be over-zealous on that point; that it is better to hold back for a little, for it is better, if you want to teach a man honesty, not to hold up before him the horrors of state prison. Children can be taught along those same lines.

(e have in New York now what we call Little Mothers' Leagues, which are formed for the purpose of instructing children on questions relating to parenthood and motherhood; and from the last meeting that I attended I was perfectly satisfied with the result of what we have done so far. Motherhood and parenthood are presented to these girls of from ten to fourteen by nurses in a manner that will elevate their whole ideas on that subject, by the discussion of papers which are left entirely to 
these girls in a dignified way, and the lack of self-consciousness with which these children discussed the subject before a mixed audience of men and women was most pleasing to us and to every nurse who listened. I would be very glad to tell you about their testimony as to what those Little Mothers' meetings can do, because we take up the girls at that receptive period; and I think the teaching along that line is what I consider the most hopeful part of our work in teaching sex hygiene, as we will have to be the instructors in all lines of hygiene in the future.

The work along the infant mortality line, relating to the public liealth question, is to be taken up in a later paper. Professor Winslow has outlined the work that is open to nurses, and I want to put in a plea for the instruction of nurses not only in personal hygiene, if that can be included, but in the preparation of reports, because in every branch of work that we are doing now the reports are an important consideration. It is not easy to teach nurses to make accurate and precise reports, and I find that a great deal of our time in instructing uurses is given to instructing in that. I feel that we are wrestling now in the battle-field of nurses, and the step that has come to us in the past year is a step in the right direction. The nurses who are appointed to the municipal civil service actually are obliged to be registered nurses. 'That has never been required before. It has raised the standard very much. I think that that has been taken up all over. I do not know whether it has been done in Chicago, but in Manhattan the nurses apply for these civil service positions and it is requested that they be registered nurses, and I feel that we have made a step in the right direction in that way. I can only rely on the teaching we are to get in the future from this ideal state of things if all our workers-because our public health nurses are social workers in the best sense-will come to us by special training; and that can only be obtained from the newer system of education. In the meantime we are working with what we have. In our own city, in our own department, nurses are educating in biological work, tuberculosis work, infant mortality work, not directly under us but in sympathy with us, nurses in the children's court and sanitary inspectors. A nurse well known to us all is doing work for the committee on the prevention of blindness.

We see how much special training we need, and if it is possible in any way to combine the practical work that we get with the theoretical work, that is the only way we can work out our own salvation.

Now so far as I am concerned I feel that the question of public health is such a large one that I would ask to be instructed by your society what direction this report should take another year. 


\section{REPORT OF THE ALMSHOUSE COMMITTEE}

To the President and Members of the Nurses' Associated Alumna of the United States:

The Committee on Almshouse Nursing begs to submit the following report. Two meetings were held during the year to consider how best to reach and help the state committees. At the first meeting it was decided to send out a circular letter with a printed form to be filled out by the various state chairmen.

The questions asked covered the following points: 1. Affiliation with women's clubs. 2. Care of sick inmates: $(a)$ medical, $(b)$ nursing, (c) isolation. 3. Occupation. 4. Entertainment. 5. Religious services.

Thirty-four letters were sent out, seventeen replies received. Most of the states heard from have done some work, and in those where no work has been done the hope was expressed that it might be taken up another year. All show an encouraging interest. Reports from the various states follow.

California.-Committee appointed three years ago found little to do, as the almshouses are in connection with the county hospitals which all have training schools for nurses. Matter to be discussed at annual ineeting.

District of Columbia.-No Almshouse Committee. The secretary promises to bring up the matter at the annual meeting of the association.

Georgia.-Has an active committee. Chairman reports that ninetytwo counties responded to requests for information. No trained nurses. Physicians called when needed. No compulsory work for inmates. One county pays inmates for work done. Three counties isolate tuberculosis inmates. Only one has regular services on Sunday. The Georgia committee seems very much alive. Will attempt some improvement in the preparation and serving of food in almshouses.

Indiana.-Standing committee. No special work reported for this year.

Illinois.-Committee is working with women's clubs. All almshouses in state investigated. Campaign being carried on along lines reported last year. The work being done through the State Federation of Women's Clubs, which for the past three years has had two or three nurses on its Philanthropy Committee.

Iowa.-In co-operation with women's clubs, almshouse conditions have been investigated. No trained nurses. Medical care not reported. Are working for isolation of sick inmates and the removal of feebleminded persons to proper homes. Four sub-committees working through state, to report at annual meeting. State chairman very enthusiastic. 
Louisiana.-No Almshouse Committee.

Missouri.-No committee. Matter to be taken up at annual meeting in October.

Nebraska.-Committee working independently. Investigation made two years ago. Medical and nursing care fairly good. No trained nurses. Some counties have outdoor wards for tubercular cases.

New Jersey.-No co-operation with clubs. Almshouses have been investigated. No trained nurses. Doctors called when needed. Sick isolated in most counties. In one county a tuberculous patient was preparing the food for the inmates. No entertainment or religious services provided.

New York.-Gradual improvement reported along all lines of work. A letter from the State Charities Association, enclosed with the report of the Chairman of the State Committee, deplores the lack of proper nursing care, and expresses the hope that much may be accomplished by the Nurses' Association in this respect.

North Carolina.-Committee working alone. No trained nursing. Physicians employed in all counties. Tuberculous inmates isolated. Only care of own room compulsory. No entertainment provided. No regular religious services.

Pennsylvania.-No committee. Matter to be taken up at next annual meeting.

Rhode Island.-No committee.

Tennessee. - No committee. Little information available. Religious services provided.

Virginia.-Committee working with women's clubs. Thirty-seven counties provide for medical care. No trained nurses. Three counties isolate tubercular patients.

Wisconsin.-Committee appointed in October. No co-operation with women's clubs. Almshouse investigated by local nurses. Much valuable information given by members of the State Board of Control.

So far as investigated but one county (Milwaukee) has regular daily visit by physician, elsewhere physician is called when needed. Two counties (Milwaukee and Marathon) have trained nurses, Marathon employing a graduate. (It might be of interest to know that Marathon County is to have the first school for consumptives in Wisconsin.) In practically all counties, almshouses are on farms. Inmates do farm and garden work. In some the clothing of the inmates is made at the institution. The local committee feels that the work in Wisconsin has only begun, and expects to make a more complete report next year.

In collecting data for this report and in conferring with state com- 
mittees and other almshouse workers, many problems have been met. which seem difficult of solution and none more so than that of employment for the inmates. What shall be done with the product of their labor? They are not skilled in any line of work and are too old to become expert when taught. Only a small part of the product could possibly be used by the institutions and that of the heavier grades of work is beyond the capacity of many old people. Sales and bazaars have been suggested, but the public grows tired of them after one or two have been given for the same purpose. We cannot depend on visitors buying them, for no one visits almshouses.

This question we have not been able to auswer satisfactorily, when it has been asked by state committees, and we would be extremely grateful if some member would suggest a solution.

The question of religious services is one that seems difficult in some states, but it should not be, for surely in every community some clergyman will be found willing to give help to these less fortunate ones.

The committee fully realizes that this report is meagre, and that little apparent progress has been made, but the letters that have come from the states show that the nurses are alive to their responsibilities and opportunities in this matter and that the leaven is working.

Respectfully submitted,

Caroline Bartlett Crane, IDA M. TICE, HeLeN W. Kelur, Chairman.

\section{REPORT OF CONFERENCE OF AMERICAN ASSOCIATION FOR THE STUDY AND PREVENTION OF INFANT MORTALITY}

The first annual meeting of the American Asociation for the Study and Prevention of Infant Mortality met in Baltimore, November 9-11, 1910. It was notable for the number of eminent people it brought together and for the great diversity of activities which they represented. It was overwhelming in the way of facts set forth and bewildering in the measures suggested for the correction of existing evils. It was inspiring in the scope of contributing interests and hopeful in the emphatic resolutions passed. A listener was almost driven to the conclusion that no aspect of life exists which does not bear directly upon infant welfare.

The sessions were so arranged that the problem was discussed in turn by philanthropists, representatives of municipal and federal governments, physicians, and educators. They showed conclusively that the study of infant mortality reaches not only to local milk stations and to the instruction of mothers, but to official standards of milk fixed by the Department of Agriculture and to the establishment of a National Board of Health; that it reaches alike to eugenics and to vital statistics; that it involves the safe-guarding of mothers 
from economic and industrial pressure but also the teaching of biology and sex-hygiene in public schools. There were five dominant facts set forth:

1. Out of 300,000 deaths of infants annually in the United States, one-third are preventable.

2. Without an accurate system of " human bookkeeping" there can be no scientific basis for attack of the problem.

3. The United States ranks with China and Turkey rather than with the civilized countries of Europe in its utter lack of trustworthy vital statistics.

4. The importance of maternal nursing is paramount to all other means of prevention of infant mortality. This was supported by the following figures of the babies who die of intestinal diseases, 80 per cent. are bottle fed, and 15 per cent. breast fed.

5. The general recognition of the imperative need of the work of nurses in the practical campaign of education and prevention.

Five resolutions were passed unanimously which clearly expressed the programme of the Association for the current year. The first urgently endorsed the movement for a National Department of Health. The second urged with equal emphasis the promotion of "the model law for the registration of births and deaths." The third was addressed to the Secretary of Agriculture, begging him to establish standards of milk branded as certified, inspected or pasteurized. The fourth besought boards licensing teachers for public schools to give as detailed tests in elementary hygiene, sanitation, and biology as are given in mathematics or in language. The fifth reads "State Boards of Education together with State Boards of Health to provide in the rural schools for conferences of mothers and for home instruction in connection with these conferences of mothers and expectant mothers and infant hygiene."

The last session was characterized by the following searching topic: * Healthy parents, right customs and wholesome environments being essential factors in preventing infant mortality, how are normal institutions fitting teachers to establish through public schools better practices in hygiene and sanitation and higher ideals of parenthood?"

The entire programme was interesting and convincing. It left a well established impression in the minds of many that the ultimate solution of the problem lay in the keeping of educators.

It was encouraging to learn that considerable effective instruction of this sort is being given in schools and colleges in various parts of the country. $A$ unique feature was presented by Dr. S. Josephine Baker, Chief of the Division of Child Hygiene of New York City (although in another session). She told of the summer school classes of "little mothers" in which there were 22.000 children last year. With the babies in their arms they came to the schools for instruction in general care and feeding of infants. Dr. Baker said, "Children are the best co-operators in the world and through them we reach the parents and accomplish reforms in the homes which would be utterly impossible in any other way."

During the discussion of preventable diseases in the second session, Miss Van Blarcom projected into the programme the subject of midwifery with such earnestness and force that a special meeting was called and a special committee appointed with power to act. It is the province of this committee to make a careful study of the varying aspects of the midwife problem through- 
out the United States, and to take such immediate action as may be deemed advisable, and to present a full report at the next meeting in Chicago.

Among thirty affiliated societies, seven nursing associations answered to roll call. Two of these were the national organizations. The delegate from Providence, R. I., read a report which showed most thorough and concerted work. Aside from these, nurses had no part in the proceedings of the convention except that Miss Nutting was a member of the Board of Directors and of a special committee. When we consider what a large share nurses have in this great movement, when we see the physician, the sanitarian, the statistician, and the social worker all leaning upon her, we must deeply regret that her voice is not more often heard among the councillors. The exhibit was perhaps quite as valuable as the discussions and doubtless reached great numbers of people who would not attend the meetings. The spirit and purpose of both are best expressed in the words of Dr. Devine: "The important thing is not merely to prevent babies from dying, but to keep them well and increase their strength, to give them the best possible beginnings for their life."

Respectfully submitted,

Ella Philltpg Crandall.

Miss Van Blarcom moved that a committee of three be appointed by the chair, to draft a resolution in regard to the care of mothers and babies by midwives. Carried. (See report of Committee on Resolutions.)

Moved that the report of the committee of the whole be taken from the table. Carried.

Dr. Hughes moved to amend Article I by adding another section as follows :

Any permanent member who has arrived at the age of sixty-two years may upon application to the Executive Committee be excused from further payment of dues, while reserving all the rights and privileges of membership.

\section{Carried.}

Motion made to amend Article IV, Section \%, by substituting " be" for "remain." Carried.

Miss Clara Noyes moved that the report of the committee of the whole be referred back to the Committee on Revision and By-laws for further consideration.

Miss McIsaAC: Madam Chairman, this membership question and eligibility question and representation question can be brought before this association next year and the year after that, and all the rest of this tremendous work be lost. It would seem to me that we might accept it and work upon that. The question of membership and revision has been before us ever since we were organized, and it is going to be before us for years. It is tremendous, and it has been gone over and over, and it is going to be gone over and over for years; and why should all the rest of this splendid work be dropped for another year and our working officers be left hampered as they are on account of it? We are not dropping it 
at all. We have got it before us and we have to do it; but why lose all this other work on account of that?

Miss Noyes: Now this seems to me a critical period in the history of the nursing profession, and we struggled with that question quite a little in the superintendents' Society, and I feel that we want all the concerted and concentrated effort that we can bring to bear upon this subject.

We must make a more careful study of this before we go further. I do not mean to say we have not made a careful study, because I think we have, and I think all the study and thought we have put upon it in the last two days has meant a tremendous amount to every one of us here. But still $I$ do think there is a great opportunity for further studying the situation of this question. The question of the organization of the American Medical Association is before my eyes-one great body divided into sections, all working more or less toward unity and harmony, but dividing into certain sections all the various forms of work. That same thing might be applied to our association, or we can come in in an individual membership, or a membership through our county associations. We have to get down to the fundamental idea of simplicity of organization.

Of course this is my feeling. It is just a personal matter with me and may not be the sentiment of the association, but I feel that I must bring it before you.

Miss Eldpedae: I would like to say that if we turn this back we cannot expect the same committee to do the work. We will start out next year just where we are to-day. There is this thing to be said about it. We have had this involved membership, and we are going to have it. The American Medical Association is a very beautiful thing to me. I have had the pleasure in my own state of attending meetings in the different branches and $I$ understand what it means. We are not as many as the doctors and we may be thankful for that. Our different sections of the country cannot be organized in the next year. We have in the city of Chicago one county, and two city associations. If we reorganize we start out with our city organization turned into Cook County, because the greater number of our nurses are there. I understand New York is situated very much in the same way. Now if we must have this involved membership why not start on it? If any one builds a house he does not pull it all to pieces just as soon as it is built because he thinks he might have improved it. He lives in it awhile and then he rebuilds. What is the use of all that you have passed upon if you now reject everything the revision committee recommends?

Miss Goonich: I felt very strongly at the beginning of this meeting that we would have to have more time to think this thing over; but as $I$ saw one change that would go into effect this year, the council of the state presidents, and realized that permanent membership is increasing, I saw that we should gradually get individual membership without any further effort to bring it about. I am very sure that our eligibility clause is going to push on our state registration work. I am quite convinced it would be a terrible thing to lose all this work, because the membership cannot be revised.

MIss Noyes: We are sometimes obliged to pull down our structure so we may build simply and well. Now if it is the feeling of this association that they want to adopt this constitution I will withdraw my motion.

The Presiment: May I say just one word of the splendid work that this committee has done; really when you come to consider it, the only question upon 
which we are in doubt is the question of membership, and we are just where we were before. The question is still before the house as to whether you will adopt this revision or not.

Dr. Hughes: I move that the by-laws be adopted subject to correction by the committee.

The President: The motion is now before the house for the adoption of the revision of the by-laws.

Miss DE WITT: May I say one word for the committee? Our ideal at the beginning of the year was for a simplifying of the membership and we put into the Joundal a tentative suggestion that it be reduced to a membership by counties, hoping to follow the lead of the American Medical Association. But we heard from all sides of the country that the nurses were not satisfied or ready to give up the alumnæe associations, or permanent membership, that the latter was a great incentive to attending the annual meetings, and we altered it at the eleventh hour to suit the majority.

The motion was put and carried.

The Phesident: I wish to congratulate you on having carried it through.

Miss Nutring: In recognition of her distinguished services to public health and welfare by providing opportunities for the further and higher education of nurses, 1 move that this association elect into honorary membership Mrs. Helen Hartley Jenkins, the founder of the first purely college work in nursing, the Departmont of Nursing and Health, Teachers' College, Columbia University.

Carried.

Miss Maxwell moved that Mrs. William K. Draper be made an honorary member.

The President: Of course you understand that these nominations for honorary membership come officially from the Board of Directors. That is according to the wording of our by-laws, and they recommend therefore these nominations for honorary members.

Mrs. Draper, as many of you know, has been connected with one of the large training schools in New York City and has probably a closer sympathy with nursing affairs than any other woman with whom $I$ have been privileged to work, unless it is the nurse herself. Mrs. Draper is a member of our National Red Cross Nursing Committee and usually in her deliberations and in her thoughts includes herself with us and says "we." She is in Boston for this convention, and I take great pleasure in presenting her name for honorary membership.

'The motion was carried.

The Nominating Committee for 1911-12 was appointed as follows:

Two appointed by the chair.-Nancy L. Dorsey, Omaha, Neb.; Ellen Persons, Chicago.

Three appointed from the floor.-Lydia A. Giberson, Philadelphia; Gertrude Selden, New York; and Ursula Noyes, Boston.

Meeting adjourned to meet at 2 P.M. 
FRIDIY ALTERNOON SESSION

The meeting was called to order at 2.15 P.M. by the president.

The Presidant: We have set apart this afternoon for the consideration of one of the most interesting problems facing us as nurses, and it seems proper that it should be presided over by one of the leaders in this particular line of work; it gives me the greatest pleasure to relinquish this meeting to Miss Ida M. Cannon, of the Social Service Department, Massachusetts General Hospital.

MIss Canion: It surely is a matter of unusual significance that so many of the papers on the programme for to-day and to-morrow are related to the duty of the nurse in the social field. Social work, of course, is not a new thing, and the spirit of social work is as old as community life; but the special function of the nurse in this field is something that we are now determining, that we are beginning to see the responsibility of.

I am not going to take time this afternoon myself, because you have people here, four of them, who can speak to you with great authority on these various subjects. Dr. Cabot, who is to give us our first paper, as you all know, has Leen very closely identified with this special line of work for the hospital community; but to those of us in Boston who know him well he is identified with many, many of these social movements; and it is to his constructive imagination and his critical judgment that not only the nurses but I think the medical profession itself owes a great deal in the way of progress towards meeting the obligations of the socializing element that is coming into our work. It is with great pleasure that I present Dr. Cabot.

\title{
HOSPITAL SOCIAL SERVICE
}

\author{
BY RICHARD C. CABOT, M.D.
}

I WENT up to Worcester not very long ago to speak on social work and the lady who introduced me said, "Now be sure before you begin to talk about the subject to tell the people what it is, because," she said, "the majority of people in your audience have never before heard the word ' social' associated with the word 'work.' 'To them ' social' means something much nearer to play, much nearer to a rest off duty than to the spirit of work."

I am going to address myself throughout the majority of the time that I shall spend in trying to make as clear as I can what it is that we have in mind when we are talking about social work. There are very few words in the language that are vaguer than those two words, and we need, I think, to try to give a little more edge, a little more point to the distinction between the social worker and the nurse and the doctor and the other factors in our modern problems. I shall try to do this by taking up a series of cases, partly imaginary, and partly real, and trying to show just what is the actual achievement or should be the actual achievements of the different people concerned in that case. 